\title{
FIRM'S STRATEGIC CHOICES AND NETWORK KNOWLEDGE DYNAMICS: HOW DO THEY AFFECT INNOVATION?
}

\section{Published in Journal of Knowledge Management}

\author{
Jose Antonio Belso-Martinez
}

Economics and Finance Department

Applied Economics Division,

University Miguel Hernández

Avda. del Ferrocarril s/n, 03202 Elche (Alicante), Spain

Tel.: 0034 966658600; Email: Jbelso@umh.es

\author{
Isabel Díez-Vial \\ Business Management Department \\ Complutense University of Madrid \\ Economics and Business School \\ Campus de Somosaguas, 28223 Madrid, Spain \\ Tel.: 0034 913942451; Email: diezvial@ccee.ucm.es
}

\begin{abstract}
:
Purpose - To explain how the evolution of knowledge networks and firms' strategic choices affect innovation. Endogenous factors associated with a path dependent evolution of the knowledge network are jointly considered with a firm's development of international relationships and increasing internal absorptive capacity over time.

Design/methodology/approach - In a Biotech cluster, we gathered data on the firms' characteristics and network relationships by asking about the technological knowledge they received in the cluster in 2007 and in 2012 - "roster-recall" method. Estimation results were obtained using moderated regression analysis.

Findings - Firms that increase their involvement in knowledge networks over time also tend to increase their innovative capacity. However, efforts devoted to building international links or absorptive capacity negatively moderate the impact of network growth on innovation.
\end{abstract}


Practical implications - Practitioners have two alternative ways of increasing innovation inside knowledge networks: they can increase their centrality by developing their knowledge network interactions or invest in developing their internal absorptive capacity and new international sources of knowledge. Investing in both of these simultaneously does not seem to improve a firm's innovative capacity.

Originality/value - Coupling firms' strategic options with knowledge network dynamics provides a more complete way of explaining how firms can improve their innovative capacity. Keywords - Knowledge, network evolution, innovation, agglomeration,

Article classification - Research paper 


\section{INTRODUCTION}

Networks have been closely associated with higher innovative capacity as they give firms greater access to valuable knowledge flows that allow them to improve their products and processes (Howells \& Bessant, 2012; Phelps, Heidl, \& Wadhwa, 2012). This is especially the case for clusters, where firms develop local flows of valuable and tacit knowledge from the relationships developed between them (Giuliani \& Bell, 2005; F. Xavier Molina-Morales \& Martinez-Fernandez, 2010; Niu, 2010). In particular, the structure of these relationships inside knowledge networks will determine a firms' innovative capacity, along with how each firm makes use of its positon inside them (Ahuja, 2000; Uzzi, 1997).

However, present network structures are conditioned by previously developed relationships, and firms trying to increase their innovative capacity have to consider not only the kind of relationships they have at present but also how these have evolved over time (Gulati, Sytch, \& Tatarynowicz, 2012; Powell, White, Koput, Smith, \& Owen-Smith, 2005). That is, firms developing their knowledge network need to consider its consequences not only for their present innovative capacity but also for their future one. Since current networks are conditioned by past relationship structures, recent network dynamic studies on clusters have focused on network evolution and its dependence on endogenous factors (Balland, De Vaan, \& Boschma, 2013; Giuliani, 2013). Different network forces have been identified to explain these network dynamics, such as a network agent's tendency to increase their centrality - preferential attachment logic -, increasing reciprocity and transitive closure between agents, or homophily toward firms in similar positons in the network, among others (Balland, 2012; Balland, BelsoMartínez, \& Morrison, 2016; Crespo, Suire, \& Vicente, 2014).

Drawing on this dynamic approach, this paper tries to understand how cluster knowledge networks evolve and their consequences for innovation. In doing so we will take into account not only endogenous network forces but also firms' strategic choices, which have seldom been analysed using this approach. Along with the aforementioned endogenous forces, networks also change due to the deliberate self-seeking actions of the firms that create these networks (Ahuja, Soda, \& Zaheer, 2012; Emirbayer \& Mische, 1998). As a result, we look at the choices firms make as they carry out resource allocation and develop the capabilities to access and assimilate the external knowledge crucial to innovation. In particular, we consider decisions made by firms which, although associated with higher knowledge flows, have also been considered a threat to the development of knowledge inside clustered networks: the establishment of international relationships and the development of individual firms' absorptive capacity. 
Taking this objective into account, we firstly try to build a theory of the mechanism through which endogenous network forces interact with the strategic choices that firms make over time. Most network dynamic studies have been at the industry level (McEvily, Jaffe, \& Tortoriello, 2012; Soda, Usai, \& Zaheer, 2004; Venkatraman \& Lee, 2004) or the dyadic level (Gulati \& Gargiulo, 1999; Gulati et al., 2012; Powell et al., 2005), but analysis at the firm level, using network structures containing the focal firm and its direct contacts ${ }^{1}$, provides valuable insights into how the evolution of the network benefits its firms (Xavier Molina-Morales \& MartínezFernández, 2009; Sammarra \& Biggiero, 2008). As long as the firms’ strategic choices induce the formation or dissolution of network links, or weaken or strengthen these, the cluster will change its structure and firms will change their strategies (Ahuja et al., 2012; Hervás-Oliver \& Albors-Garrigós, 2007).

In particular, we will look at the establishment of international links. These have been broadly considered as a key element in improving the knowledge flows in clustered networks: firms have different knowledge bases, offering new opportunities for novel combinations of knowledge and other complementary resources (Hohenthal, Johanson, \& Johanson, 2014). Firms can develop a gatekeeping role, connecting international and domestic sources of knowledge (Giuliani, 2011; Kontinen \& Ojala, 2011), although these benefits are not so straightforward as they have to invest time and effort in local interactions that may not be as beneficial (Morrison \& Rabellotti, 2009). By considering the evolution of the network over time, we dissipate doubts on how both types of relationship architectures - international and local - should be managed.

Finally, this paper contributes by evaluating how the development of an individual firm's absorptive capacity affects the benefits derived from its knowledge network. Investments in absorptive capacity enhance a firm's ability to assimilate and replicate the knowledge acquired from others (Cohen \& Levinthal, 1990; Giuliani \& Bell, 2005). Moreover, the reinforcement of the knowledge base combined with the firm's engagement in local networks exercises valuable synergistic effects (Cassiman \& Veugelers, 2006). Nevertheless, strong evidence exists when the longitudinal perspective is considered (Petruzzelli, Albino, Carbonara, \& Rotolo, 2010). These strategies are resource consuming and time intensive, so firms find it difficult to develop both network links and absorptive capacity simultaneously without unplanned leaks of internally created knowledge (Morrison \& Rabellotti, 2009).

\footnotetext{
${ }^{1}$ Networks consisting of a focal firm, nodes with which the focal firm is directly connected plus the ties among the alters are frequently called ego-networks.
} 


\section{THEORETICAL FRAMEWORK AND HYPOTHESES}

\subsection{The growth of the network}

The structure of the knowledge network plays an important role in determining a firm's innovation by conditioning the type and value of resources, ideas and knowledge received from other firms (Phelps et al., 2012). However, firms inside these networks also need to devote time and effort to accruing potential knowledge gains. In this sense, network centrality has been widely considered a crucial structural characteristic of networks in terms of improving innovation through access to status, power and valuable resources (Ahuja, 2000; Gnyawali \& Madhavan, 2001).

From a longitudinal perspective, firms tend to become increasingly central through progressively building new links. As they increase their centrality, firms try to overcome technological limitations and pursue different research lines through access to complementary inputs in a fast and accurate way (Ahuja, 2000; Madhavan, Koka, \& John, 1998). The formation of these new ties tends to follow the rule of "preferential attachment", because firms tend to link with those that are already linked to others in order to benefit from a larger pool of valuable resources (Balland et al., 2013; Brass, Galaskiewicz, Greve, \& Tsai, 2004; Powell et al., 2005). When there is little information about potential sources of advice, status frequently acts as a signpost for firms to identify repositories of valuable information, so firms that are already central become even more central (Giuliani, 2013).

Along with higher centrality, network evolution also affects changes in common goals, norms and reciprocal expectations regarding the trustworthiness of the exchange (Borgatti \& Foster, 2003). The existence of self-reinforcing governance mechanisms, such as shared norms and values that tend to be developed between firms in the same network, also contributes to diminishing free-riding problems and misunderstandings between parties sharing knowledge (J. A. C. Baum, McEvily, \& Rowley, 2012). Furthermore, accumulated relational experiences due to presence in former networks promotes a sort of "network memory" that evolves with the creation and dissolution of links, affecting the present network structure and outcomes (Ahuja et al., 2012; Gulati \& Gargiulo, 1999; Soda et al., 2004). Common understanding, a consequence of the retrieval of past interactions, improves a firm's capacity to absorb, sift and classify new technical developments in a way that goes well beyond the processing abilities of a firm "per se" (Ahuja, 2000). Even if new firms enter the knowledge network and others leave, this "network memory" remains and this facilitates innovation by creating a kind of collective 
routine that eases communication and coordination through the network. Based on these arguments, we propose that:

\section{Hypothesis 1. "Greater knowledge network centrality over time increases innovation".}

Nevertheless, for either central or peripheral firms, the preferential attachment logic fosters centrality in the network by increasing the number of a firm's direct contacts with new or incumbent firms. As Rivera et al. (2010) recently highlighted, firms tend to seek self-similar alters in their position in the network because they are more likely to be willing to share their knowledge and resources (Boschma \& Ter Wal, 2007), so a trustworthy relationship tends to be developed and dominant logic is created at the network and community levels (Owen-Smith \& Powell, 2004).

Firms showing strong centrality preferably connect to other central nodes, while peripheral nodes engage with other peripheral nodes in a process of "positive assortativity" (Newman, 2002; Watts, 2004) or "structural homophily" (Crespo et al., 2014). By including more central firms in its portfolio of ties, a central firm can take advantage of benign spill-over effects in terms of visibility, stability and status, and access more valuable information and resources (Ahuja, 2000; Gulati \& Gargiulo, 1999; Powell, Koput, \& Smith-Doerr, 1996). However, more importantly, if multiple central nodes simultaneously aspire to establish more links with other prevalent actors in the network, a mutual reinforcing effect emerges. Over time, this mutually beneficial circle results in greater centrality for all the actors involved.

This positive assortativity among central firms creates an on-going tendency towards stable core-periphery structures, characterised by a dense nucleus of highly connected firms. Within this sub-network or core group (Newman, 2002), the strength of the links increases the willingness to share knowledge and favours the acquisition and absorption of knowledge from alters (Levin \& Cross, 2004). The corollary is immediate as thanks to positive assortative dynamics, central firms become even more central and the benefits accrued from a greater number of direct ties among similar firms tend to be increasingly underpinned. Therefore, we expect that:

Hypothesis 2. "The positive effect on innovation of greater knowledge network centrality over time is positively moderated by the centrality of the firm's alters",

\subsection{The influence of firms' strategic choices}


A firm's knowledge network evolves not only due to endogenous forces (e.g. preferential attachment, positive assortative mixing), but also to its unilateral strategic choices (Ahuja et al., 2012; Giuliani, 2013). As Hervás-Oliver \& Albors-Garrigós (2007: 117) have pointed out: "The active role of clustered firms can be analysed both from the firm's external aspect, or the strategies which connect the firm to the cluster's available resources, and from the firm's internal aspect, i.e. the firm's strategies and its contribution to the cluster".

Firms may strategically decide to engage in international links in order to benefit from nonredundant knowledge and new ways of thinking that are useful for increasing innovation (Jeremy Howells, 2006). In doing so these firms, which behave as gatekeepers, also provide benefits for their connections in the cluster (Petruzzelli et al., 2010)

It has been broadly assumed that firms establishing international relationships can minimise this problem of being locked into the existing knowledge network. As clusters evolve toward a central-peripheral structure, they tend to develop shared routines and patterns that can create a lock-in effect and reduce innovative capacity (F. Xavier Molina-Morales \& MartínezFernández, 2009). Firms that have connections with international players become gatekeepers, creating the knowledge network relationships with other markets and thus avoiding the cost of others maintaining these simultaneously (Morrison, 2008). That is, they tend to develop a knowledge creation role (Hervas-Oliver \& Albors-Garrigos, 2014).

Nevertheless, from the point of view of the firm that tries to combine international links with local ones, these benefits are not so clear. First, the creation and maintenance of international links is a strategic choice that requires time and effort and this seems hard to reconcile with developing and maintaining a robust presence within the cluster network. By their very nature, distant links are less perdurable as they require time and a brokerage role (Burt, 2000; Soda et al., 2004). Compared to cluster ties, maintaining non-local relationships is costlier due to dissimilarities and a lack of cohesiveness (Burt, 2002). The different norms and routines prevailing in each industry hinder the management of distant partnerships and make the successful internalisation of shared knowledge more difficult (Baum et al., 2012). As a consequence, these relationships tend to be short lived and frequently renewed, unless huge investments lead to the embeddedness required to make them long lasting (Bell \& Zaheer, 2007; Burt, 2002).

Second, one would expect firms to be reluctant to share knowledge from international markets with other firms in their knowledge networks (Morrison \& Rabellotti, 2009; Shaver \& Flyer, 
2000). To avoid distributing knowledge unintentionally, the firms that behave as gatekeepers and connect others may establish selective diffusion strategies that reduce their involvement in the local cluster (Morrison, 2008). There seems to be a trade-off between maintaining increasingly central local positions and international links, as they both require time and effort (Crespo et al., 2014). Given this argument, we hypothesise that:

Hypothesis 3. "The positive effect on innovation of greater knowledge network centrality over time is negatively moderated by international links"

Absorptive capacity allows cluster firms to successfully internalise and apply external knowledge (Hervás-Oliver \& Albors-Garrigos, 2009; Niu, 2010). As firms develop a greater capacity to generate new knowledge for developing new product designs or manufacturing processes, mainly through internal investment in $R \& D$, they also develop their ability to identify, understand and exploit external knowledge from the local network (Boschma \& Ter Wal, 2007; Giuliani \& Bell, 2005). Inside the network, knowledge flows have different effects depending on a firm's absorptive capacity, as a firm's internal resources shape the amount of knowledge that they can incorporate (Hervas-Oliver, Albors-Garrigos, de-Miguel, \& Hidalgo, 2012).

This fact turns investment in this crucial capability into another strategic choice that may influence the dynamics of the network, along with the establishment of international relationships.

The emergence and value of this synergistic effect between a firm's internal knowledge base and its knowledge networks, observed at a particular point in time, may only be fully appreciated if a network dynamic approach is applied. While having both centrality and a solid knowledge base foster innovation, firms may find it difficult to synchronise the development of their absorptive capacity and the enlargement of their local networks over time. Hiring new R\&D staff enhances absorptive capacity by incorporating new experiences and solutions to specific problems (Cohen \& Levinthal, 1990) that subsequently diffuse within the organisation through the internal communication systems (Hervas-Oliver et al., 2012). New knowledge can only be incorporated into the firm's knowledge base when it has been shared and assimilated into organisational routines and practices and this requires time and resources (Cohen \& Levinthal, 1990).

The assets, social context, culture and portfolio of knowledge-based activities in which the firm is involved are the consequence of present and past decisions. Firms are therefore propelled 
towards a specific learning path determined by a set of specific routines and procedures reflecting the knowledge trajectory of the firm (Zahra \& George, 2002). Under resource constraints, the cultivation of such assets and processes may become untenable with developing new external relationships or increasing interactions at the cluster level (Belso-Martinez \& Molina-Morales, 2013; Francesc Xavier Molina-Morales \& Expósito-langa, 2012)

From the perspective of a network as a whole, the benefits largely depend on the contribution of its member firms. Firms with solid knowledge bases derived from internal investments enhance local externalities and collective efficiency. However, active involvement in knowledge networks may not always be attractive for firms investing in their absorptive capacity (Morrison \& Rabellotti, 2009). Unilaterally, firms may find little incentive to share the gains of their enhanced capabilities due to potential opportunistic behaviour or unplanned leaks to rivals (Cassiman \& Veugelers, 2006). So firms exhibiting high absorptive capacity become more selective in the creation of links or progressively reduce their number of partners. In contrast, poor absorptive capacity implies reliance and extra effort in the formation of ties with local knowledge sources. Taking these arguments into account, we propose that:

Hypothesis 4. "The positive effect on innovation of greater knowledge network centrality over time is negatively moderated by increases in the firm 's absorptive capacity"

\section{METHOD AND EMPIRICAL EVIDENCE}

In this section we describe the main issues relating to our empirical research: presentation of the geographical context selected; exploratory analysis and data-related issues; social network analysis considerations, including its suitability and implementation; the variables; and finally the quantitative statistics comprising the regression analysis, graphical examination of interaction effects and the results.

\subsection{The Biotech cluster in Alicante (Valencia region)}

The Spanish Bioindustry Association (ASEBIO) identifies 3,025 firms performing biotechnology-related activities and these account for $7.15 \%$ of GDP and 38,724 jobs. Biotechnology is the main activity of 660 firms, representing an increase of $7 \%$ since 2010 ( ASEBIO Report, 2013). Within this specific group, only $3.2 \%$ have more than 250 employees. Innovation dynamics are based on private funding (67.7\%) as well as cooperation between firms and public organisations. Extensive cooperation with universities and other public research bodies is reported by $75.2 \%$ and $53.3 \%$ of biotech firms respectively. Interactions within the 
private sector also appear to be relevant, particularly those of a vertical nature (46.4\%) or with providers of knowledge-intensive services (42.6\%).

When comparing geographical differences, we observe some regions where the industry is relatively overrepresented or underrepresented. The Valencia region, accounting for $7.63 \%$ of the total number of biotech firms, ranks behind Catalonia (18.54\%) and Madrid (15.49\%). Even so, this Mediterranean area is gaining importance as the number of firms rose sharply from 22 to 66 over the 2003-2010 period. Successful projects such as the BIOVA meeting platform, have decisively contributed to the creation of fertile ground for the development of the sector. Recently, a strong science base and a supportive business environment have led to the emergence of a strong group of interconnected firms and public organisations in the southern part of the region. Four universities, seven research centres, ten hospitals, two science parks and business incubators have created the necessary scientific environment and resulted in collaborative research with the industry, the creation of spin-offs and entrepreneurship. In particular, we should highlight the role of Miguel Hernández University and its top research institutes: the Neuroscience institute, an unit associated with the Spanish Research Council that has 201 full-time researchers; the Bioengineering institute, composed of nine different research units and over 100 researchers; and the Institute of molecular and cellular biology, a centre of excellence at a national level and committed to basic applied research on bioactive molecules.

Although the cluster's 31 firms are spread across a populated area of $50 \mathrm{~km}$, most of them are located near the sources of capital and scientifically-skilled personnel in the urban area of Elche-Alicante. Small and medium sized enterprises specialising in medical and agricultural biotech activities predominate, accounting for $43 \%$ and $35.71 \%$ respectively. The average size per unit is approximately 22.5 employees and slightly over two million euros of turnover. Cluster structure and initiatives increasingly appear to be managed by the Asociación Empresarial de Biotecnología de Alicante (AEBA). Created in 2012, this specialist local organisation led by experienced entrepreneurs is designed to generate synergies and foster an entrepreneurial business environment.

\subsection{Data and sample issues}

We tested our hypotheses using firm data collected from the Biotech cluster during 2013. Prior to the main fieldwork, selective in-depth interviews were conducted with experts and practitioners to obtain a thorough understanding of the cluster and industry. The insights obtained allowed for the design of our questionnaire and enriched the discussion of our results. 
Once pre-tested, our questionnaire was administered to business owners and senior managers by a skilled technician. Each interview lasted around 45 minutes and gathered data on the firm's characteristics, innovation practices, inter-organisational relationships and performance. In order to pool data on different measures over time, informants were asked to report information at two selected moments, 2007 and 2012. Respondents who were not working for their companies on the first of these dates were persuaded to attend the meeting with somebody else who was employed at that time. The longitudinal structure of our data minimises endogeneity concerns and allows us to hypothesise about the direction of causality.

Our research was not based on a sample as data were gathered from all biotech firms populating the cluster. As no specific database existed, a full list of firms and public organisations was obtained by combining records from the most important local organisations: Bioval and AEBA. Of the 31 biotech firms populating the cluster, a total of 28 agreed to participate, yielding an appropriate response rate of slightly more than $90 \%$. Despite the small number of observations, by selecting this cluster we have followed SNA methodological considerations on cluster size and ensured a reliable recreation of the full local knowledge network. In this vein, peer debriefing with local experts confirmed that all of the most important local players were considered. As expected, nearly all firms reported close technological cooperation with local universities and public research centres (93\% in 2012).

Scholars support retrospective reporting as a viable methodology (De Vaus, 2001; Featherman, 1980). However, debate still exists over the reliability of the data due to possible cognitive distortions (Golden, 1992; Huber \& Power, 1985). Several features of our research, such as its chronological structure and inclusion of clues, mitigate inaccuracies and favour reliable data capture (Miller, Cardinal, \& Glick, 1997). In addition, we enhanced verisimilitude by explaining our questionnaire to reluctant participants and restricting the recall time to recent years (Miller et al., 1997).

At the beginning of the meeting we explained the benefits of the project, guaranteed confidentiality and offered access to the results to encourage the provision of accurate data (Miller et al., 1997). Once participants had started the survey, our expert interviewer guided them through the different questions by asking for specific examples, facts or events. In addition, he repeatedly emphasised that questions should be answered on the basis of real situations during the relevant time span. These efforts for the retrieval of past experiences have been proven to increase the effectiveness and accuracy of this methodology (Golden, 1992; Miller et al., 1997). 


\subsection{Social Network Data}

Inter-firm networks offer a favourable space through which knowledge can be created and exchanged, but appropriate tools must be implemented in order to study their development and impact. Social network analysis (SNA) provides an explicit formal method to map and measure these relationships, regardless of whether they are informal (e.g. developed through personal interactions) or formal (e.g. cooperation agreements or R\&D projects). In our case, SNA makes the relationship among a group of clustered firms visible and analyses it, with the underlying premise that the behaviour of the firms is impacted by, and in turn shapes, their relationship architecture. This technique has gained considerable attention in both management (e.g. Molina-Morales et al. 2015; Alberti \& Pizzurno 2015) and cluster literature (Balland et al., 2016; Boari, Molina-Morales, \& Martínez-Cháfer, 2016; Francesc Xavier Molina-Morales \& Martínez-Cháfer, 2014), due to its suitability for the assessment of the topology of complex social networks and information exchanges.

Data to conduct SNA can be collected in various ways depending on their nature. For informal relationships, the most common way is through a questionnaire. Consequently, prior to the SNA (Liebowitz, 2005) we applied the "roster-recall" method to identify inter-firm knowledge-based relationships (Boschma \& Ter Wal, 2007; Giuliani \& Bell, 2005; Morrison \& Rabellotti, 2009). As previously mentioned, the cluster population size and the data collection process make this methodology suitable (Ter Wal \& Boschma, 2009). During the interview, each respondent was given a roster on which the names of relevant cluster firms were already given. Based on this list and a free recall area, we asked them to indicate from which companies technological knowledge had been received, and which counterparts benefited from the technological knowledge transferred by that firm. Both questions were made with reference to 2007 and 2012, and were rated on a scale of 0-3 to represent the importance of the connections. ${ }^{2}$ Using this procedure we collected specific network data to construct the knowledge network developed inside the cluster.

\subsection{Variables}

The dependent variable in this model is the innovation of firms, defined in terms of each firm's innovative capacity in 2012. This variable combines information from seven items related to product and process innovations and reported satisfactory internal reliability ( $\square$-Cronbach of

\footnotetext{
${ }^{2}$ With which of the following firms on the list have you regularly exchanged technological information over the last three years?)
} 
0.78). Respondents were asked to judge whether over the last three years their firms had: introduced new products, introduced new services, significantly improved products before their competitors, significantly improved services before their competitors, implemented new or enhanced manufacturing methods; applied novel logistics solutions; and used new or improved supporting activities for manufacturing processes.

For the operationalisation of the explanatory variables we start from the knowledge network constructed from the importance of the technological knowledge received from each firm, as has been previously explained (Giuliani \& Bell, 2005). Growth in knowledge network centrality ( $\triangle$ Firm's centrality) was measured as the difference between the number of direct ties -degreefor the two periods considered: 2007 and 2012 (Madhavan et al., 1998; Suitor, Wellman, \& Morgan, 1997). That is, we have measured centrality for a given period as the total number of direct links that configure the firm's network (Freeman, 1979). Based on a similar measure of centrality growth, we measured the growth of the firm's network centrality ( $\triangle$ Firm's network centrality) as the difference between the average degree of the firm's direct links in 2012 and 2007. This measure takes into account not only a firm's increased centrality but also the centrality growth of its direct contacts.

International relationships (International relationships) was calculated as the mean score from eight items indicating the existence of links with foreign suppliers, customers, competitors, universities, public research centres, private research centres, other subsidiaries of the same corporation, consultancy and advisory services (Bell \& Zaheer, 2007). Therefore, the numerical value of this variable will range from " 0 ", non-existence of foreign organisational relationships, to "1", maximum number of relationships with foreign actors. In this sense, we have followed previous studies, mainly on international business. The measurement of this variable is based on previous studies considering different agents in international markets when it comes to succeeding in the internationalisation process (Eriksson et al., 1997; Rugman, A.M. \& D’Cruz, 2000; Schwens \& Kabst, 2009)

The absorptive capacity of firms (Absorptive capacity) was proxied through the ratio of workers holding a university degree or devoted to R\&D to the firm's total workforce (Boschma \& Ter Wal, 2007; Giuliani \& Bell, 2005). The index value for each company was obtained as the equally weighted sum of the percentage of employees with university degrees and the percentage of employees assigned to R\&D. While we just control for this variable, in this research we specifically conjecture about the effect of increases in the firm's absorptive capacity ( $\triangle$ Absorptive capacity) on innovation. To avoid estimation problems, $\Delta$ Absorptive 
capacity was measured in a different way and did not come from changes in Absorptive capacity over the period considered. We assess the firm's efforts to increase absorptive capacity by asking respondents whether or not the firm has recruited more personnel with experience in: a) business management, b) $R \& D$ in the public sector; c) $R \& D$ in the private sector. Next, the scores obtained in these three dummy-coded variables were combined into a single index ranging from zero (if the firm had not hired any experienced employees) to three (if the firm had hired employees from the three aforementioned profiles).

The first control variable is firm age (Age), which is measured as the number of years for each firm since its foundation. Prior research suggest that older biotech firms have more developed innovation capabilities (J. a. C. Baum, Calabrese, \& Silverman, 2000). Firm size (Size) should also be considered as a control variable when evaluating the effects of network variables on innovation performance. Consequently, we controlled for firm size by using the total number of employees in 2012. This operationalisation seems advisable since many biotech firms have limited revenues or tangible assets. In addition, we have taken into account the influence of supporting organisations. Two dummy-coded variables were used to reflect links with the main supporting organisations (Bioval and $A E B A$ ). We assigned the value one if a firm was a member of the organisation concerned and zero otherwise.

Table 1 shows the means, standard deviations and correlations for the study's variables. The highest correlation is under 0.80 which, following (Hair, Anderson, Tatham, \& Balck, 1998) is an indication against the possible presence of multicollinearity.

---Insert Table 1 around here---

\subsection{Analysis and Results}

Using data collected from the Alicante Biotech cluster we constructed two different technological knowledge networks at two points in time, the technological network in 2007 and that in 2012. Each of these networks involves $n=28$ actors and can be represented as a directed and binary $n^{*} n$ graph $x=\left(x_{i j}\right)$, where $x_{i j}=1$ when actor $i$ discloses having requested technological advice from actor $j(i, j=1, \cdot n)$. The resulting network structures are binary (" 1 " if there is technological advice, "0" otherwise). As we have already mentioned, we dichotomised the relationship data. Values of 1 to 3 were collapsed into just one category to 
reflect the existence of links (value 1). In contrast, 0 was applied where there was evidence of the non-existence of ties.

Table 2 summarises the main characteristics of the technological networks in 2007 and 2012. As can be observed, the 2012 network displays a higher total average centralisation, density and a smaller number of isolated conditions compared with the 2007 network. This indicates that over the last five years firms have become more correlated and interconnected. The propensity for reciprocity, a measure of the extent to which a tie is reciprocated, and the propensity for transitivity, an indicator of the tendency towards triadic closure ("friends of friends become friends") are slightly lower in the 2012 network.

\section{---Insert Table 2 around here---}

Regression analysis was selected to test the hypotheses because it offers the opportunity to include three interactions while controlling for certain firm-level characteristics. We ran four models to assess the explanatory power of each set of variables. Note that subscript ' $i$ ' denotes firms and $\varepsilon$ is the error term. In order to assess the accuracy and reliability of our results we confirmed the regression assumptions with the single overall test and the help of residuals of fitted models.

---Insert Table 3 around here---

Table 3 contains four different models. The baseline model includes the control variables: Size, Absorptive capacity, and Bioval and AEBA (relationships with supporting organisations). A second model also contains an interaction term obtained from the cross product of centrality growth and the increase in the firm's absorptive capacity ( $\triangle$ Firm's centrality $* \Delta$ Absorptive capacity). The third model adds International relationships and a new interaction term calculated by multiplying International relationships by centrality growth ( $\triangle$ Firm's centrality * International relationships). The final model includes changes in a firm's network centrality ( $\triangle$ Firm's network centrality) and the interaction term calculated as the growth of the firm's centrality multiplied by the growth of the firm's network centrality ( $\triangle$ Firm's centrality * $\Delta$ Firm's network centrality).

Our findings provide robust support for our expectations. The main influence of the growth in centrality is always positive and significant (p-value<0.01), so Hypothesis 1 is strongly supported. In Model 2, the multiplicative variable representing the combined effect of simultaneously improving the firm's absorptive capacities and having centrality growth appears 
to be negatively related to innovative capacity at the $\mathrm{p}$-value $<0.1$. Consequently, Hypothesis 2 is also endorsed.

The inclusion in Model 3 of the variables connected to International relationships shows the importance to innovation of developing gatekeeping roles with distant agents, and the detrimental effect caused by making parallel networking efforts at both the internal network and international levels. Hypothesis 3 is supported at $p$-value $<0.05$. In our final model the main effect of the degree of growth of a firm's network is a negative impact on innovation ( $\mathrm{p}$ value $<0.01$ ). In contrast, a positive sign at $p$-value $<0.1$ is reported for the interaction term obtained by the cross product of the firm's centrality growth and the growth of the firm's network centrality. According to our estimation, Hypothesis 4 is ratified. Control variables reflecting firm level characteristics and internal resources are non-significant, while only being a member of the recently created business association AEBA exerts a negative effect on innovation (p-value $<0.10)$.

Graphical representations refine some of the results for the hypotheses. Following AIKEN AND WEST (1991), figures 1-3 represent the interaction effects using values of the moderator variable. Simple regression lines were generated to introduce these values into the regression equation.

---Insert Figure 1 around here---

Figure 1 shows how the contribution of centrality growth is quite pronounced for firms exhibiting lower increases in their absorptive capacity. Over time, these particular firms are more likely to increase their innovation through links inside the cluster. However, from the slopes obtained we observe that this trend does not hold for firms with high increases in their absorptive capacity. So, possibly due to resource limitations, firms should be cautious about their innovation-related strategies and time the construction of absorptive capacity and internal connectedness.

---Insert Figure 2 around here---

Figure 2 represents the interaction effect of centrality growth and international links on innovation capacity. Centrality growth's contribution presents a pattern that is somewhat similar to the former case. Development of links inside the cluster is positively associated with innovative capacity for firms that are relatively weakly internationalised. For firms with high levels of international connections, this positive effect becomes slightly negative. In other words, our results highlight the importance for innovation of local connections for firms in the 
early stages of their internationalisation process, regardless of their position within the cluster network. However, once firms pass a threshold of international connectedness, successive investments in local networking do not generate the same effect. It seems that extra efforts in local connectedness may affect other innovation-related activities due to resource restrictions, harming innovation performance.

---Insert Figure 3 around here---

Figure 3 shows the significant interaction effect for centrality growth and changes in the average degree of the firm's network. The positive impact on innovation caused by an increase in the firm's number of direct partners grows as networks become richer through higher degree members.

\section{Discussion}

We have firstly confirmed that firms following a preferential attachment process when forming their ties tend to increase innovation. This preferential attachment logic implies that biotech firms with many ties are more likely to receive new ties in the future. Over time, this creates a kind of cumulative advantage for increasingly connected firms in the network, leading to outstanding innovation. These results are consistent with previous studies in other contexts that have also confirmed this tendency of local central firms to become more central, creating a strong central core inside the network (Gulati \& Gargiulo, 1999; Morgan, Neal, \& Carder, 1996; Powell et al., 2005). These results confirm that firms prefer to attract well-connected partners, but also that central positions inside a cluster have cumulative advantages over time (Sun \& Liu, 2016).

Underlying the benefits of this preferential attachment process is also the existence of prior experience and shared norms that reflect a road map in which established relationships facilitate new giving-receiving knowledge relationships. This path dependence phenomenon leads to a self-reinforcing growth of local interactions, generating a benign "lock-in" effect that may explain the better adaptive capacity and development over time of more central firms. Beyond emphasising a predictable evolution rooted in the network memory, what seems extremely interesting is the potential underpinning effect attributable to innovation success. Higher performance inevitably results in moves to strengthen the formation of ties under the auspices of path dependence and preferential attachment logic. The reproduction of this cycle of network formation, innovation and reinforcement fortifies the systemic shared norms and values which drive the predictability of the evolution of the whole network structure and industrial system. 
Secondly, we have observed that this positive relationship between increasing centrality over time and innovation is reinforced through a firm's direct contacts also increasing their centrality. Interestingly, we demonstrate that central firms expanding their network by connecting to others exhibiting a similar structural network evolution (i.e. positive assortativity) achieve greater innovation performance. Such findings are consistent with the theoretical models of network formation (e.g. Westbrock, 2010), suggesting that the topology of the network and the centrality of its members are crucial in determining the formation of links.

Network path dependence rooted in the preferential attachment rule and based on a collective network memory implies density and access to external resources from partners exhibiting similar centrality scores. While it may help firms to develop the necessary routines and procedures for garnering, interpreting and exploiting the knowledge of others, it can hamper their capacity to identify new and more radical sources and combinations of knowledge. (Hervás-Oliver, Albors-Garrigos, \& Baixauli, 2012). In fact, firms investing in their internal absorptive capacity seem to prefer to temporarily increase their innovation relying more on the reinforcement of their internal knowledge base than on enriching local central relations.

Finally, a firm's strategic options for establishing direct international relationships and obtaining fresh and new knowledge tend to reduce the relative benefits associated with access to local sources of knowledge, as previous studies have observed (Morrison \& Rabellotti, 2009). Clustered firms establishing international relationships behave as gatekeepers, which in this emerging cluster development stage may have positive effects on the cluster as a whole (Hervas-Oliver \& Albors-Garrigos, 2014). Nevertheless, at firm level we observe that trying to combine domestic and international connections means establishing a selective strategy.

The findings relating to absorptive capacity suggest that firms find it difficult to invest simultaneously in strengthening clustered knowledge relationships and establishing distant ones. To be beneficial, central positions require both time and effort and this may not be compatible with establishing and maintaining external relationships (Shaver \& Flyer, 2000). This is particularly the case for small and medium sized enterprises, whose resource constraint induces them to both invest in internal resources and rely more extensively on network relationships as a source of knowledge and experience (Zeng, Xie, \& Tam, 2010).

\section{CONCLUSIONS}

The role of knowledge networks in increasing a firm's innovative capacity has been a central topic for academics from different managerial perspectives. Recent studies from a network 
dynamic perspective have highlighted the importance of understanding the evolution of the network as a path dependent process. That is, firms need to consider the consequences of their knowledge relationships not only for their present innovative capacity but also for their future one. Similarly, many studies have explained the important role played by establishing international relationships and increasing absorptive capacity in increasing a firm's innovative capacity. By taking these different approaches jointly we have obtained interesting insights, mainly relating to the kind of trade-off faced by innovative firms in a cluster.

First, firms can improve their innovative capacity by investing in their clustered knowledge network. The network's tendency to establish core-periphery structures, driven by endogenous and self-reinforcing processes, means that firms become increasingly centrally positioned. This centrality is reinforced over time by establishing connections with other firms that are also central -assortativity mixing. The results obtained in this research indicate that it is not just a question of reaching and maintaining strong positions at a precise moment in time, but rather of improving the firm's relative position through links with partners involved in these same efforts. By belonging to this "core" group of firms, they have access to complementary resources, ideas and knowledge, while also having more status and power. That is, not all positions in a network of clustered firms can access and exploit existing knowledge. Rather, central firms have access to selective sources of knowledge that foster innovation by successfully combining knowledge.

Second, firms need to develop specific strategies to be able to access certain knowledge from the cluster. Firms can increase their innovative capacity by developing their own self-interest strategies, mainly by establishing international relationships and improving their internal absorptive capacity. In doing so, firms can avoid a certain lock-in effect that tends to appear in knowledge networks, while also improving their capacity to assimilate and exploit external sources of knowledge. Ideally, firms could benefit from both centrality in the clustered knowledge network and their involvement in these strategies. However, a longitudinal perspective throws some light on the difficulties inherent to this dual focus. Firms that try to obtain benefits from both sources simultaneously tend to underperform compared to firms that focus on just one source at a time. It would be better to alternate periods of developing the network with periods of developing each firm's individual strategies.

Taking these results into account we can establish the following managerial implications for those who wish to increase their innovative capacity. First, managers need to be selective about the cluster network. They must develop increasingly central positions, searching for other firms 
that have valuable resources, reputations, or many other connections. Secondly, knowledge acquired inside cluster networks needs to be reinforced with international and internal sources of knowledge, but these complementary sources of knowledge need to be incorporated sequentially.

This research has some limitations that could be taken into account when carrying out future research. First, we have collected data from a Biotech cluster during the growth stage of its life cycle. Following Ter Wal and Boschma (2011), networks co-evolve with the life cycle of an industry or cluster, with the high stability in core-peripheral structures expected in growth stages not necessarily being present in mature or introductory stages. As a consequence, we must be cautious in generalising the conclusions to other contexts. Further research could try to examine in greater depth the dynamics of local networks in different stages of the industry life cycle. For instance, the benefits of being in central positions that we have found might not hold in mature stages where the risk of redundancies, excessive regulations or the need for additional resources from peripheral firms might arise (Baum, Calabrese, \& Silverman, 2000; Rothaermel \& Deeds, 2004).

Second, in this research we have paid attention to firms in order to achieve a better picture of the role of a firm's agency behaviour. In this sense, it would be interesting to closely examine the role that alliances have in the dynamics of the cluster and the evolution of core-periphery structures through the formation of triadic closure structures (Ter Wal, 2014).

Third, data were captured using retrospective reporting. Although we are confident about their validity and reliability and the roster recall method offered us detailed and valuable information about the network, potential bias is derived from self-perceptions and any omissions that may exist. In this sense, future research could be developed based on secondary data such as patent citations (Demirkan \& Demirkan, 2012) that can also offer a longitudinal perspective of the evolution of the biotech network, taking into account other aspects of the relationships or the different changing rates of the variables under analysis.

Finally, the population targeted in this study was firms located in the Biotech cluster of Alicante. Thus, care should be taken when extrapolating our results to other clusters or industries. Additionally, although the small number of observations cannot be considered a limitation because it directly derives from the composition of the cluster, this situation restricts the possibilities for econometric analysis and its potential. 


\section{REFERENCES}

Ahuja, G. (2000). Collaboration networks, structural holes, and innovation: A longitudinal study. Administrative Science Quarterly, 45(3), 425-455.

Ahuja, G., Soda, G., \& Zaheer, A. (2012). The genesis and dynamics of organizational networks. Organization Science, 23(2), 434-448.

Aiken, L. S., \& West, S. G. (1991). Multiple regression: Testing and interpreting interactions. United Kingdom: Sage Publications.

Alberti, F. G., \& Pizzurno, E. (2015). Knowledge exchanges in innovation networks: evidences from an Italian aerospace cluster. Competitiveness Review, 25(3), 2015. https://doi.org/10.1108/CR-01-2015-0004

Balland, P. A. (2012). Proximity and the Evolution of Collaboration Networks: Evidence from Research and Development Projects within the Global Navigation Satellite System (GNSS) Industry. Regional Studies, 46(6), 741-756. https://doi.org/10.1080/00343404.2010.529121

Balland, P. A., Belso-Martínez, J. A., \& Morrison, A. (2016). The dynamics of technical and business knowledge networks in industrial clusters: embeddedness, status or proximity? Economic Geography, 92(1), 35-60. https://doi.org/http://dx.doi.org/10.1080/00130095.2015.1094370

Balland, P. A., De Vaan, M., \& Boschma, R. A. (2013). The dynamics of interfirm networks along the industry life cycle: The case of the global video game industry, 1987-2007. Journal of Economic Geography, 13(5), 741-765. https://doi.org/10.1093/jeg/lbs023

Baum, J. a. C., Calabrese, T., \& Silverman, B. S. (2000). Don't go it alone: alliance network composition and startups' performance in Canadian biotechnology. Strategic Management Journal, 21(3), 267-294. https://doi.org/10.1002/(SICI)10970266(200003)21:3<267::AID-SMJ89>3.0.CO;2-8

Baum, J. A. C., McEvily, B., \& Rowley, T. J. (2012). Better with age? Tie longevity and the performance implications of bridging and closures. Organization Science, 23(2), 529-546.

Bell, G. G., \& Zaheer, A. (2007). Geography, networks, and knowledge flow. Organization Science, 18(6), 955-972. https://doi.org/10.1287/orsc.1070.0308

Belso-Martinez, J. A., \& Molina-Morales, F. X. (2013). Non-linear relationships of internal and external resources on a firm's innovation: The case of the spanish vinalopo footwear cluster. Growth and Change, 44(3), 494-521. https://doi.org/10.1111/grow.12017

Boari, C., Molina-Morales, F. X., \& Martínez-Cháfer, L. (2016). Direct and Interactive Effects of Brokerage Roles on Innovation in Clustered Firms. Growth and Change. https://doi.org/10.1111/grow.12170

Borgatti, S. P., \& Foster, P. C. (2003). The network paradigm in organizational research: a review and typology. Journal of Management, 29(6), 991-1013. https://doi.org/10.1016/S01492063

Boschma, R. A., \& Ter Wal, A. L. J. (2007). Knowledge networks and innovative performance in an industrial district: The case of a Footwear District in the south of Italy. Industry \& Innovation, 14(2), 177-199.

Brass, D. J., Galaskiewicz, J., Greve, H. R., \& Tsai, W. (2004). Taking stock of networks and organizations: a multilevel perspective. The Academy of Management Journal, 47(6), 795-817. 
Burt, R. S. (2000). The network structure of social capital. Research in Organizational Behavior, 22, 345-423. https://doi.org/10.1016/S0191-3085(00)22009-1

Burt, R. S. (2002). Bridge decay. Social Networks, 24(4), 333-363. https://doi.org/10.1016/S0378-8733(02)00017-5

Cassiman, B., \& Veugelers, R. (2006). In search of complementarity in innovation strategy: Internal R\&D and external knowledge acquisition. Management Science, 52(1), 68-82.

Cohen, W. M., \& Levinthal, D. A. (1990). Absorptive capacity: A new perspective on learning and innovation. Administrative Science Quarterly, 35(1), 128-152. https://doi.org/10.2307/2393553

Crespo, J., Suire, R., \& Vicente, J. (2014). Lock-in or lock-out? How structural properties of knowledge networks affect regional resilience? Journal of Economic Geography, 14(1), 199-219.

De Vaus, D. A. (2001). Research design in social research. London: Sage Publications.

Demirkan, I., \& Demirkan, S. (2012). Network characteristics and patenting in Biotechnology, 1990-2006. Journal of Management, 38(6), 1892-1927. https://doi.org/10.1177/0149206311408319

Emirbayer, M., \& Mische, A. (1998). What Is Agency? American Journal of Sociology, 103(4), 962-1023.

Eriksson, K., Johanson, J., Majkagard, A., Sharma, D. D. D., Majkgard, A., \& Sharma, D. D. D. (1997). Experiential knowledge and cost in the internationalization process. Journal of International Business Studies, 28(2), 337-360.

Featherman, D. L. (1980). Retrospective longitudinal research: Methodological considerations. Journal of Economics and Business, 32(2), 152-169.

Freeman, L. C. (1979). Centrality in social networks conceptual clarification. Social Networks, 1 , 215-239.

Giuliani, E. (2011). Role of technological gatekeepers in the growth of industrial clusters : Evidence from Chile. Regional Studies, 45(10), 1329-1348.

Giuliani, E. (2013). Network dynamics in regional clusters: Evidence from Chile. Research Policy, 42(8), 1406-1419. https://doi.org/10.1016/j.respol.2013.04.002

Giuliani, E., \& Bell, M. (2005). The micro-determinants of meso-level learning and innovation: evidence from a Chilean wine cluster. Research Policy, 34(1), 47-68. https://doi.org/10.1016/j.respol.2004.10.008

Gnyawali, D. R., \& Madhavan, R. (2001). Cooperative networks and competitive dynamics: A structural embeddedness perspective. Academy of Management Review, 26(3), 431-445.

Golden, B. (1992). The past is the past - or is it? The use of retrospective accounts as indicators of past strategy. Academy of Management Journal, 35(4), 848-860.

Gulati, R., \& Gargiulo, M. (1999). Where do interorganizational networks come from? American Journal of Sociology, 104(5), 1439-1493.

Gulati, R., Sytch, M., \& Tatarynowicz, A. (2012). The rise and fall of small worlds: Exploring the dynamics of social structure. Organization Science, 23(2), 449-471.

Hair, J., Anderson, R., Tatham, R., \& Balck, W. (1998). Multivariate data analysis. Englewood Cliffs: Prentice-Hall.

Hervas-Oliver, J.-L., \& Albors-Garrigos, J. (2014). Are technology gatekeepers renewing 
clusters? Understanding gatekeepers and their dynamics across cluster life cycles.

Entrepreneurship \& Regional Development, 26(5-6), 431-452.

https://doi.org/10.1080/08985626.2014.933489

Hervás-Oliver, J.-L., \& Albors-Garrigos, J. (2009). The role of the firm's internal and relational capabilities in clusters: when distance and embeddedness are not enough to explain innovation. Journal of Economic Geography, 9(2), 263-283.

https://doi.org/10.1093/jeg/lbn033

Hervás-Oliver, J.-L., \& Albors-Garrigós, J. (2007). Do clusters capabilities matter? An empirical application of the resource-based view in clusters. Entrepreneurship \& Regional Development, 19(2), 113-136. https://doi.org/10.1080/08985620601137554

Hervás-Oliver, J.-L., Albors-Garrigos, J., \& Baixauli, J. J. (2012). Beyond R\&D activities : the determinants of firms' absorptive capacity explaining the access to scientific institutes in low-medium-tech contexts. Economic of Innovation and New Tecnology, 21(1), 55-81.

Hervas-Oliver, J.-L., Albors-Garrigos, J., de-Miguel, B., \& Hidalgo, A. (2012). The role of a firm's absorptive capacity and the technology transfer process in clusters: How effective are technology centres in low-tech clusters? Entrepreneurship \& Regional Development, 24(7-8), 523-559. https://doi.org/10.1080/08985626.2012.710256

Hohenthal, J., Johanson, J., \& Johanson, M. (2014). Network knowledge and businessrelationship value in the foreign market. International Business Review, 23(1), 4-19. https://doi.org/10.1016/j.ibusrev.2013.08.002

Howells, J. (2006). Intermediation and the role of intermediaries in innovation. Research Policy, 35(5), 715-728. https://doi.org/10.1016/j.respol.2006.03.005

Howells, J., \& Bessant, J. (2012). Introduction: Innovation and economic geography: a review and analysis. Journal of Economic Geography, 12(5), 929-942. https://doi.org/10.1093/jeg/lbs029

Huber, G., \& Power, D. (1985). Retrospective reports of strategic-level managers: Guidelines for increasing their accuracy. Administrative Science Quarterly, 6(2), 171-180.

Informe ASEBIO 2012.Situación y tendencias del sector de la biotecnología en España. (2013). Madrid.

Kontinen, T., \& Ojala, A. (2011). Network ties in the international opportunity recognition of family SMEs. International Business Review, 20(4), 440-453. https://doi.org/10.1016/j.ibusrev.2010.08.002

Levin, D. Z., \& Cross, R. (2004). The strength of weak ties you can trust: The mediating role of trust in effective knowledge transfer. Management Science, 50(11), 1477-1490. https://doi.org/10.1287/mnsc. 1030.0

Liebowitz, J. (2005). Linking social network analysis with the analytic hierarchy process for knowledge mapping in organizations. Journal of Knowledge Management, 9(1), 76-86. https://doi.org/10.1108/13673270510582974

Madhavan, R., Koka, B. R., \& John, E. (1998). How industry networks in transition: relationships events (re)shape interfirm relationships. Strategic Management Journal, 19(5), 439-459.

McEvily, B., Jaffe, J., \& Tortoriello, M. (2012). Not all bridging ties are equal: network imprinting and firm growth in the Nashville Legal Industry, 1933-1978. Organization Science, 23(2), 547-563.

Miller, C., Cardinal, L., \& Glick, W. (1997). Retrospective reports in organizational research: A reexamination of recent evidence. Academy of Management Journal, 40(1), 189-204. 
Molina-Morales, F. X., Belso-Martinez, J. A., Mas-Verdu, F., Martinez-Chafer, L., Xavier Molina-Morales, F., Belso-Mart??nez, J. A., ... Mart??nez-Ch??fer, L. (2015). Formation and dissolution of inter-firm linkages in lengthy and stable networks in clusters. Journal of Business Research, 68(7), 1557-1562. https://doi.org/10.1016/j.jbusres.2015.01.051

Molina-Morales, F. X., \& Expósito-langa, M. (2012). The impact of cluster connectedness on firm innovation: R\&D effort and outcomes in the textile industry. Entrepreneurship \& Regional Development, 24(7-8), 685-704. https://doi.org/10.1080/08985626.2012.710257

Molina-Morales, F. X., \& Martínez-Cháfer, L. (2014). Cluster Firms: You'll Never Walk Alone. Regional Studies, 50(5), 877-893. https://doi.org/10.1080/00343404.2014.952719

Molina-Morales, F. X., \& Martinez-Fernandez, M. T. (2010). Social networks: effects of social capital on firm innovation. Journal of Small Business Management, 48(2), 258-279.

Molina-Morales, F. X., \& Martínez-Fernández, M. T. (2009). Too much love in the neighborhood can hurt: How an excess of intensity and trust in relationships may produce negative effects on firms. Strategic Management Journal, 30(3), 1013-1023. https://doi.org/10.1002/smj

Morgan, D. L., Neal, M. B., \& Carder, P. (1996). The stability of core and peripheral networks over time. Social Networks, 19(1), 9-25.

Morrison, A. (2008). All Gatekeepers of knowledge within industrial districts: who they are, how they interact. Regional Studies, 42(6), 817-835. https://doi.org/10.1080/00343400701654178

Morrison, A., \& Rabellotti, R. (2009). Knowledge and information networks in an Italian wine cluster. European Planning Studies, 17(7), 983-1006. https://doi.org/10.1080/09654310902949265

Newman, M. (2002). Assortative mixing in networks. Physical Review Letters, 89(20), 208701-1208701-4. https://doi.org/10.1103/PhysRevLett.89.208701

Niu, K. (2010). Organizational trust and knowledge obtaining in industrial clusters. Journal of Knowledge Management, 14(1), 141-155. https://doi.org/10.1108/13673271011015624

Owen-Smith, J., \& Powell, W. W. (2004). Knowledge networks as channels and conduits: The effects of spillovers in the Boston Biotechnology community. Organization Science, 15(1), 5-21.

Petruzzelli, A. M., Albino, V., Carbonara, N., \& Rotolo, D. (2010). Leveraging learning behavior and network structure to improve knowledge gatekeepers' performance. Journal of Knowledge Management, 14(5), 635-658. https://doi.org/10.1108/13673271011074818

Phelps, C., Heidl, R., \& Wadhwa, A. (2012). Knowledge, networks, and knowledge networks: A review and research agenda. Journal of Management, 38(4), 1115-1166. https://doi.org/10.1177/0149206311432640

Powell, W. W., Koput, K. W., \& Smith-Doerr, L. (1996). Interorganizational and the collaboration locus of innovation: Networks of learning in Biotechnology. Administrative Science Quarterly, 41(1), 116-145.

Powell, W. W., White, D. R., Koput, K. W., Smith, J. O., \& Owen-Smith, J. (2005). Network dynamics and field evolution: The growth of interorganizational collaboration in the Life Sciences. American Journal of Sociology, 110(4), 1132-1205. https://doi.org/10.1086/421508

Rivera, M. T., Soderstrom, S. B., \& Uzzi, B. (2010). Dynamics of dyads in social networks: Assortative, relational, and proximity mechanisms. Annual Review of Sociology, 36(1), 
91-115. https://doi.org/10.1146/annurev.soc.34.040507.134743

Rothaermel, F. T., \& Deeds, D. L. (2004). Exploration and exploitation alliances in biotechnology: a system of new product development. Strategic Management Journal, 25(3), 201-221. https://doi.org/10.1002/smj.376

Rugman, A.M., \& D’Cruz, J. R. (2000). Multinationals as flagship firms: Regional Business Networks. Oxford: Oxford University Press.

Sammarra, A., \& Biggiero, L. (2008). Heterogeneity and specificity of inter-firm knowledge flows in innovation networks. Journal of Management Studies, 45(4), 800-829.

Schwens, C., \& Kabst, R. (2009). How early opposed to late internationalizers learn: Experience of others and paradigms of interpretation. International Business Review, 18(5), 509-522. https://doi.org/10.1016/j.ibusrev.2009.06.001

Shaver, J. M., \& Flyer, F. (2000). Agglomeration economies, firm heterogeneity, and foreign direct investment in the United States. Strategic Management Journal, 21(12), 11751193.

Soda, G., Usai, A., \& Zaheer, A. (2004). Network memory: The influence of past and current networks on performance. Academy of Management Journal, 47(6), 893-906.

Suitor, J. J., Wellman, B., \& Morgan, D. L. (1997). It's about time: How, why, and when networks change. Social Networks, 19(1), 1-7. https://doi.org/10.1016/S03788733(96)00287-0

Sun, Y., \& Liu, K. (2016). Proximity effect, preferential attachment and path dependence in interregional network: a case of China???s technology transaction. Scientometrics, 108(1), 201-220. https://doi.org/10.1007/s11192-016-1951-0

Ter Wal, A. L. J. (2014). The dynamics of the inventor network in German biotechnology: geographic proximity versus triadic closure. Journal of Economic Geography, 14(3), 589620. https://doi.org/10.1093/jeg/lbs063

Ter Wal, A. L. J., \& Boschma, R. A. (2009). Applying social network analysis in economic geography: framing some key analytic issues. Annals of Regional Science, 43(3), 739756. https://doi.org/10.1007/s00168-008-0258-3

Ter Wal, A. L. J., \& Boschma, R. A. (2011). Co-evolution of firms, industries and networks in space. Regional Studies, 45(7), 919-933.

Uzzi, B. (1997). Social structure and competition in interfirm networks: The paradox of embeddedness. Administrative Science Quarterly, 42(1), 35-67.

Venkatraman, N., \& Lee, C. (2004). Preferential linkage and network evolution: a conceptual model and empirical test in the U.S. video game sector. The Academy of Management Journal, 47(6), 876-892.

Watts, D. J. (2004). The "New" Science of Networks. Annual Review of Sociology, 30(1), 243 270. https://doi.org/10.1146/annurev.soc.30.020404.104342

Westbrock, B. (2010). Natural concentration in industrial research collaboration. The RAND Journal of Economics, 41(2), 351-371.

Zahra, S. A., \& George, G. (2002). Absorptive capacity: a review, reconcptualization, and extension. Academy of Management Review, 27(2), 185-203.

Zeng, S. X. X., Xie, X. M. M., \& Tam, C. M. M. (2010). Relationship between cooperation networks and innovation performance of SMEs. Technovation, 30(3), 181-194. https://doi.org/10.1016/j.technovation.2009.08.003 
Table 1: Correlations and main descriptive statistics

\begin{tabular}{|c|c|c|c|c|c|c|c|c|c|}
\hline Size & 1 & & & & & & & & \\
\hline Age & $* * * .515$ & 1 & & & & & & & \\
\hline Bioval & 0.211 & 0.205 & 1 & & & & & & \\
\hline AEBA & $* 0.311$ & 0.088 & 0.156 & 1 & & & & & \\
\hline Absorptive capacity & $* * *_{-} 0.591$ & $* * *_{-} 0.528$ & -0.202 & -0.078 & 1 & & & & \\
\hline$\Delta$ Firm's centrality & 0.274 & 0.116 & 0.268 & 0.256 & $*_{-} *_{-} .384$ & 1 & & & \\
\hline$\Delta$ Absorptive capacity & 0.178 & 0.178 & -0.016 & $* * * 0.588$ & -0.202 & 0.147 & 1 & & \\
\hline International relationships & 0.132 & 0.132 & -0.100 & $* * * 0.566$ & -0.033 & 0.180 & $* * 0.443$ & 1 & \\
\hline$\Delta$ Firm's network centrality & -0.298 & $* *_{-} 0.518$ & 0.133 & -0.117 & $* * .430$ & -0.250 & $*_{-0.357}$ & -0.195 & 1 \\
\hline Mean & 4.211 & 7.892 & 0.143 & 0.321 & 0.723 & 0.714 & 1.786 & 0.345 & 0.405 \\
\hline $\mathrm{Sd}$ & 2.987 & 5.286 & 0.356 & 0.478 & 0.277 & 1.997 & 0.917 & 0.226 & 2.066 \\
\hline
\end{tabular}

Significance level $* * * 0.01 ; * * 0.05 ; * 0.1$ 
Table 2. Summary of technological knowledge networks

\begin{tabular}{lccc}
\hline & In 2007 & In 2012 & Variation (\%) \\
\cline { 2 - 4 } Density & 0.067 & 0.073 & 8.96 \\
Edges & 51 & 55 & 7.84 \\
Reciprocity & 0.896 & 0.886 & -1.12 \\
Transitivity & 0.242 & 0.236 & -2.48 \\
Centralization (degree) & 0.187 & 0.26 & 39.04 \\
Centralization (betweenness) & 0.067 & 0.126 & 88.06 \\
\hline
\end{tabular}


Table 3: Estimation results using moderated regression analysis. Dependent variable: Innovative capacity

\begin{tabular}{|c|c|c|c|c|}
\hline & Model 1 & Model 2 & Model 3 & Model 4 \\
\hline Intercept & $* * 0.473(0.235)$ & $* * * 0.612(0.204)$ & $* * * 0.593(0.203)$ & $* * * 0.587(0.214)$ \\
\hline Size & $0.017(0.018)$ & $0.005(0.015)$ & $0.010(0.015)$ & $0.014(0.148)$ \\
\hline Age & $0.004(0.009)$ & $-0.004(0.008)$ & $-0.004(0.008)$ & $-0.006(0.009)$ \\
\hline Bioval & $0.063(0.116)$ & $0.044(0.098)$ & $0.080(0.099)$ & $* 0.197(0.104)$ \\
\hline AEBA & $-0.103(0.113)$ & $-0.071(0.096)$ & $-0.148(0.103)$ & $-0.117(0.096)$ \\
\hline Absorptive capacity & $0.001(0.002)$ & $-0.002(0.002)$ & $-0.001(0.002)$ & $0.001(0.002)$ \\
\hline$\Delta$ Firm's centrality & $* * 0.058(0.022)$ & $* * * 0.193(0.049)$ & $* * * 0.130(0.032)$ & $0.020(0.022)$ \\
\hline$\Delta$ Absorptive capacity & $* * 0.116(0.055)$ & $* * * 0.210(0.056)$ & $* * 0.122(0.046)$ & $* * 0.11(0.048)$ \\
\hline International relationships & & & $* 0.342(0.181)$ & \\
\hline$\Delta$ Firm's network centrality & & & & $* * *-0.077(0.021)$ \\
\hline$\Delta$ Absorptive capacity $* \Delta$ Firm's centrality & & $* * *-0.079(0.026)$ & & \\
\hline International relationships $* \Delta$ Firm's centrality & & & $* * *-0.239(0.080)$ & \\
\hline$\Delta$ Firm's network centrality $* \Delta$ Firm's centrality & & & & $* * 0.025(0.009)$ \\
\hline Multiple $\mathrm{R}^{2}$ & 0.493 & 0.656 & 0.692 & 0.805 \\
\hline Adjusted $\mathrm{R}^{2}$ & 0.315 & 0.511 & 0.539 & 0.658 \\
\hline F-Statistic (sig.) & $* * 2.776$ & $* * * 4.531$ & $* * * 4.505$ & $* * * 5.493$ \\
\hline $\mathrm{N}$ & 28 & 28 & 28 & 28 \\
\hline
\end{tabular}


Figure 1. Two-way interaction effect of $\Delta$ firm's centrality and $\Delta$ absorptive capacity on innovation
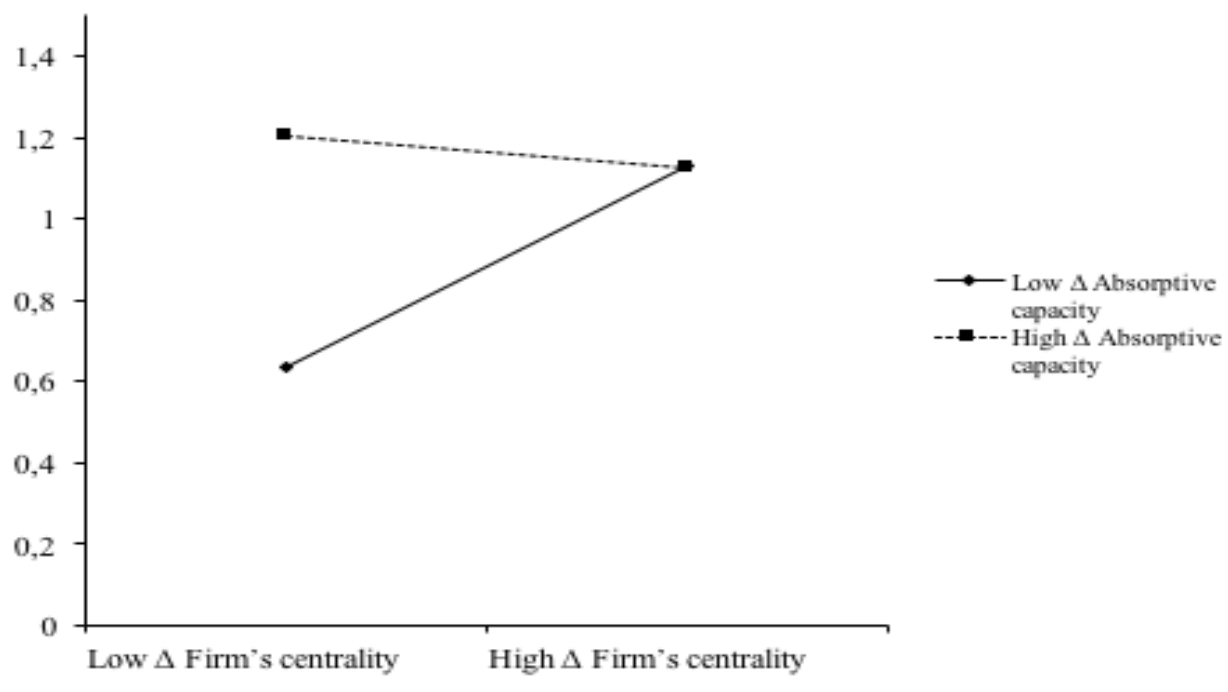
capacity

Figure 2. Two-way interaction effect of $\Delta$ firm's centrality and international relationships on innovation

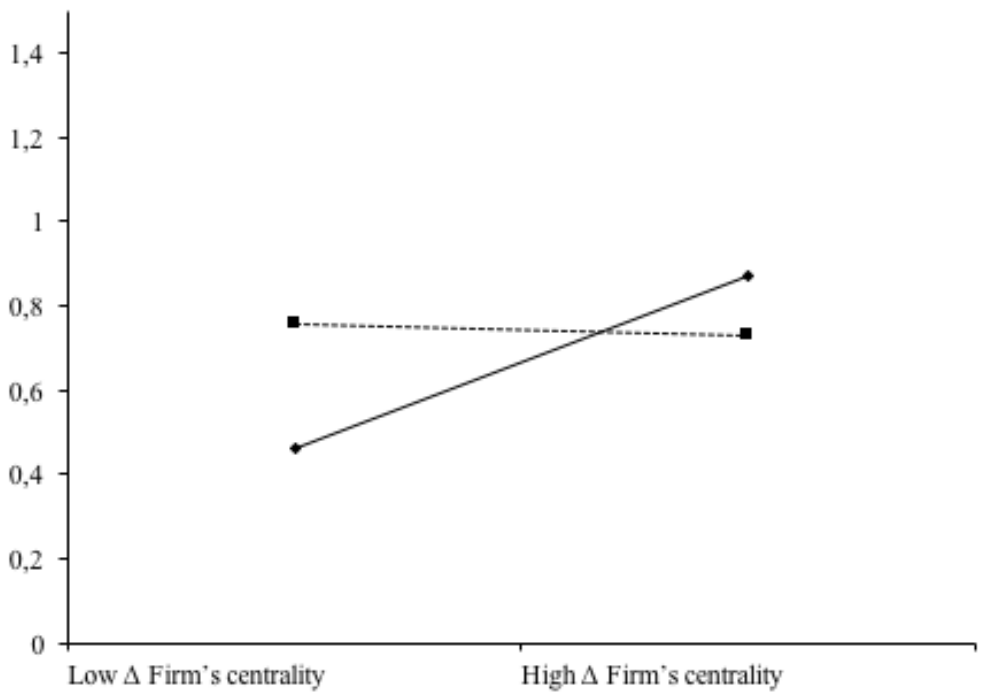


Figure 3. Two-way interaction effect of $\Delta$ firm's centrality and $\Delta$ firm's network centrality on innovation

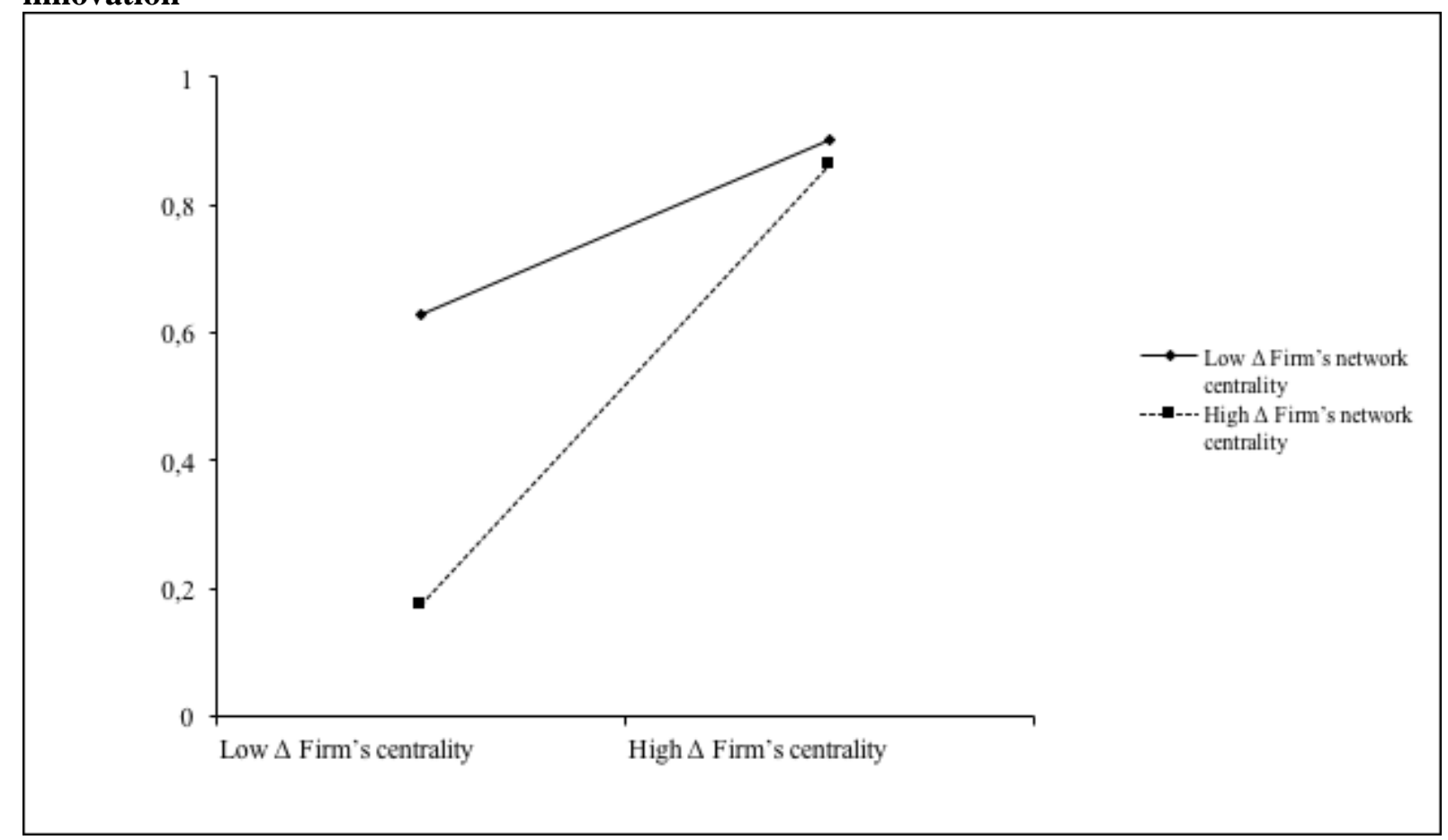

